\title{
Selective oxidation of hydrocarbons in a catalytic dense membrane reactor:
}

\section{Catalytic properties of BIMEVOX $(\mathrm{Me}=\mathrm{Ta})$}

\author{
A. Löfberg ${ }^{1}$, H. Bodet ${ }^{1}$, C. Pirovano ${ }^{2}$, M.C. Steil ${ }^{2}$, R.N. Vannier ${ }^{2}$, E. Bordes-Richard ${ }^{1}$ \\ ${ }^{1}$ Laboratoire de Catalyse de Lille, UMR CNRS 8010 \\ ${ }^{2}$ Laboratoire de Cristallochimie et Physicochime du Solide, UMR CNRS 8012 \\ USTL-ENSCL, 59655 Villeneuve d'Ascq, France, Axel.Lofberg@univ-lille1.fr
}

\begin{abstract}
Used as dense membranes in a catalytic dense membrane reactor, $\mathrm{Bi}_{2} \mathrm{~V}_{0.8} \mathrm{Ta}_{0.2} \mathrm{O}_{5.5}$ (BITAVOX) is more or less active in the oxidation of propane, ethane and propene according to its surface roughness. When the surface roughness is low, membranes are poorly active in the oxidation of propane (Conversion $<2 \%$ ). $\mathrm{CO}$ and propene are the main products and the stability is high over long experimental periods. BITAVOX membranes with increased surface roughness exhibit high conversions in the oxidation of propane, ethane and propene. Activities and selectivities evolve with time. In a first short period $(<250$ s), products are similar to those of polished samples, then mainly $\mathrm{H}_{2}$ and $\mathrm{CO}$ are produced and subsequently $\mathrm{H}_{2}$ and coke. These evolutions are probably related to surface and sub-surface restructuring due to an insufficient oxygen supply through the membrane to face the high catalytic activity induced by the increase in surface area. The results suggest that the $\mathrm{O}^{2-}$ diffusion is limited by the low electronic conductivity of BIMEVOX materials. Nevertheless the membrane is not reduced irreversibly, even in coking conditions. This is confirmed by ex-situ characterisations carried out on the materials (XRD, SEM, XPS). An improvement of the electronic conductivity of this material is necessary in order to stabilize the intermediate catalytic behaviour which is interesting for syngas or $\mathrm{H}_{2}$ production from light hydrocarbons.
\end{abstract}


Keywords: Dense membrane reactor, BIMEVOX, BITAVOX, ethane, propane, propene oxidation, syngas, hydrogen.

\section{Introduction}

The catalytic dense membrane reactor (CDMR) is a means to study and to optimize the catalytic behaviour of oxides, because it allows to decouple the two steps of the redox mechanism that prevails in selective oxidation of hydrocarbons [1-4]. One can expect an increase in selectivity to valuable products if oxygen is not co-fed with the hydrocarbon, as it has already been demonstrated by DuPont for n-butane oxidation to maleic anhydride in a circulating fluid bed reactor [5-7].

Our CDMR assembly allows combined studies of the catalytic reaction (activity, selectivity, etc.) and of the solid catalytic membrane (ionic conductivity, permeability, electrolyte potentiometry). The catalytic dense membrane separates two compartments, fed by the (diluted) hydrocarbon on the reactant side and by diluted oxygen on the oxidizing side. At the high oxygen partial pressure side (HOP), $\mathrm{O}_{2}$ is reduced to $\mathrm{O}^{2-}$ species which diffuse through the membrane towards the low oxygen partial pressure side (LOP). The gradient of oxygen activity between the two sides of the membrane is the driving force of $\mathrm{O}^{2-}$ diffusion. Finally $\mathrm{O}^{2-}$ may recombine to form gaseous $\mathrm{O}_{2}$ (semipermeability to $\mathrm{O}_{2}$ ) or, preferably, may react with the hydrocarbon. In the absence of an external electrical circuit, electrons must flow through the membrane simultaneously and counterwise to $\mathrm{O}^{2-}$. Candidate materials for use in a CDMR must therefore exhibit convenient properties for oxidation catalysis, as well as high ionic and electronic conductivities, and finally a good stability.

BIMEVOX materials, based on the $\gamma-\mathrm{Bi}_{4} \mathrm{~V}_{2} \mathrm{O}_{11}$ structure in which $\mathrm{V}$ is partially substituted by $\mathrm{ME}=\mathrm{Co}, \mathrm{Cu}$, Ta, etc., exhibit high oxygen conductivities at moderate temperatures (625-875 K) [8]. Although their oxide ion conductivity is about 100 times higher than that of yttria- 
stabilised zirconia at the same temperature, their semipermeability to oxygen gas is poorer because of low rates of oxygen exchange at the surface and low electronic conductivity [9, 10]. However, as already shown [11], this is not a drawback for the use of BIMEVOX in membrane reactors. First, these properties lead to strong polarisation of the membranes which contributes to their good stability, even at the low oxygen pressure side of the membrane. Second, only small amounts of gaseous $\mathrm{O}_{2}$ may flow in the LOP compartment and thus homogeneous gas phase reactions are limited which helps to satisfy safety issues. Finally, it limits the oxygen readsorption, which is the scope of redox decoupling. The catalytic properties of cobalt and copper substituted BIMEVOX (BICOVOX and BICUVOX) have already been examined in the oxidative dimerisation of propene (fixed bed reactor [12] and CDMR [11]) and the oxidation of propane on both mirror polished and unpolished membranes [13].

In the present paper the catalytic oxidation of $\mathrm{C}_{2}-\mathrm{C}_{3}$ hydrocarbons (ethane, propane, propene) using BITAVOX membranes with different surface roughnesses is studied and the results are compared to those obtained with BICUVOX and BICOVOX membranes.

\section{Experimental}

$\mathrm{Bi}_{2} \mathrm{~V}_{0.8} \mathrm{Ta}_{0.2} \mathrm{O}_{5.5}$ (BITAVOX) powder was synthesized from pure oxides. Dense membranes $(\varnothing=15 \mathrm{~mm}, \mathrm{~d}=1.5 \mathrm{~mm}, \mathrm{~m}=2-2.5 \mathrm{~g}$, relative density $>95 \%)$ were shaped and sintered at $1148 \mathrm{~K}$. The catalytically active side of the disk was polished using 800 grit SiC paper (noted BITAVOX-800) or 220 grit SiC paper (BITAVOX-220) in order to obtain samples with increasing surface roughnesses. Membranes were placed between two mullite tubes sealed by means of pyrex glass O-rings. Details of the experimental setup have been published elsewhere [11]. In brief, the gas phase composition at inlets and outlets of the two compartments of the CDMR was monitored using a mass spectrometer (Omnistar Pfeiffer) for 
catalytic reaction and an oxygen gauge (Setnag) for $\mathrm{O}_{2}$ permeation studies. First, the oxygen permeation properties were measured by flowing pure He and air in the LOP and HOP compartments, respectively. Then, ethane, propane or propene $\left(1 \%\right.$ in $\mathrm{He}, \mathrm{F}=50 \mathrm{~cm}^{3} \cdot \mathrm{min}^{-1}$, contact time, $\tau=2.4 \mathrm{~s}$ ) was flowed in LOP. Parameters such as temperature (823-973 K) and oxygen partial pressure $\left(2 \times 10^{4}-10^{5} \mathrm{~Pa}\right)$ at the HOP side of the membrane were varied. In all cases, the total pressure in both compartements was atmospheric pressure. The surface polarization at the LOP side (Solid Electrolyte Potentiometry - SEP) was determined in situ by measuring the electric potential difference between two gold electrodes, a grid (counter electrode) and a tip (working electrode) in contact with the HOP and LOP sides, respectively. Measurements of the conductivities in fonction of oxygen partial pressure were performed $\left(\mathrm{T}=823-973 \mathrm{~K}, \mathrm{pO}_{2}=10^{-1}-10^{5} \mathrm{~Pa}\right)$ using a 1260 Solartron frequency analyser. Both sides of the membranes were characterized by scanning electron microscopy (SEM-EDX), X-ray diffraction (XRD) and X-ray photoelectron spectroscopy (XPS) before and after reaction.

\section{Results}

\section{Semipermeability to gaseous $\mathrm{O}_{2}$}

Whatever the membrane, the amount of permeating dioxygen is low $\left(\mathrm{pO}_{2}^{\mathrm{LOP}}<100 \mathrm{~Pa}\right)$ whereas the polarization measured by SEP is high. Indeed, according to temperature and $\mathrm{pO}_{2}{ }^{\mathrm{HOP}}$, the difference of potential $\left(\Delta \mathrm{E}_{\text {exp }}\right)$ is in the range $[-25,-1] \mathrm{mV}$. These values are far from those calculated with the Nernst equation considering the LOP surface is in equilibrium with the measured $\mathrm{pO}_{2}{ }^{\mathrm{LOP}}\left(\Delta \mathrm{E}_{\text {equi }}=-200\right.$ to $\left.-300 \mathrm{mV}\right)$. This suggests, as in the case of $\mathrm{Cu}$ and Co substituted BIMEVOX $[11,13]$, that the step of oxygen recombination at the LOP surface $\left(2 \mathrm{O}^{2-} \rightarrow \mathrm{O}_{2}+4 \mathrm{e}^{-}\right)$limits the $\mathrm{O}_{2}$ permeation process. 
BITAVOX with intermediate surface roughness - as compared to mirror-polished and to 220 SiC grit paper polished samples - has been studied in propane oxidation. Figure 1 shows the results obtained for BITAVOX-800 at $923 \mathrm{~K}$. The reaction reaches rapidly the steady state as it can be seen from the stable pressures of reaction products. Conversion reaches a minimum of about $2 \mathrm{~mol} \%$ then shows a slow increase to $3 \mathrm{~mol} \%$. Considering that the reaction products' pressures are stable it is probable that the evolution in conversion is due to instabilities in the reactant flow. $\mathrm{CO}$ is the main oxidation product $\left(\mathrm{S}_{\mathrm{CO}}=38 \mathrm{~mol} \%\right)$, followed by propene $\left(\mathrm{S}_{\mathrm{C} 3 \mathrm{H} 6}=34 \mathrm{~mol} \%\right)$, ethylene $\left(\mathrm{S}_{\mathrm{C} 2 \mathrm{H} 4}=19 \mathrm{~mol} \%\right)$ and methane $\left(\mathrm{S}_{\mathrm{CH} 4}=9 \mathrm{~mol} \%\right)$ (selectivities $\mathrm{S}$ are expressed in moles of propane converted to the considered product, values indicated are those obtained at $\mathrm{t}=1500 \mathrm{~s}) . \mathrm{H}_{2}$ production is low $\left(\mathrm{pH}_{2}=17 \mathrm{~Pa}\right.$ at steady state $)$ resulting in a $\mathrm{H}_{2} / \mathrm{CO}$ ratio of about 0.4 . The selectivity to syngas is thus very low. Indeed, although the $\mathrm{H}_{2} \mathrm{O}$ pressure may not be measured experimentally, it may be estimated by mass balance calculations on $\mathrm{H}$-containing molecules at about $50 \mathrm{~Pa}$ (at steady state), that is about 3 times higher than that of $\mathrm{H}_{2}$. From mass balance calculations, and by subsequent oxidation of the LOP surface by flowing air in LOP, it can also be affirmed that no or very little coking occurs during the reaction.

\section{Catalytic properties of BITAVOX-220}

As already observed with other BIMEVOX membranes with high surface roughness $(\mathrm{Me}=$ $\mathrm{Cu}, \mathrm{Co}[13])$, BITAVOX-220 exhibits a transient behaviour during the oxidation of propene, ethane or propane (Fig. 2). In the case of propene, the initial conversion $(\mathrm{C}=60 \mathrm{~mol} \%)$ drops rapidly until a steady state is reached $(\mathrm{C}=30-35 \mathrm{~mol} \%)$. $\mathrm{CO}$ and $\mathrm{H}_{2}$ are the main products in the initial stage of reaction, whereas $\mathrm{H}_{2}$ and coke are formed when the activity is stabilized. The conversions of propane and of ethane follow similar trends in the initial stage of reaction, 
reaching a maximum at ca. 55-60 mol\%. Then they decrease to values below $10 \mathrm{~mol} \%$. Again, in this final stage $\mathrm{H}_{2}$ and coke are the major products.

Figure 3 shows the distribution of the reaction products obtained during propane oxidation along reaction time. $\mathrm{CO}$ and $\mathrm{H}_{2}$ are initially the main products and their amounts increase steadily as conversion increases. During the first $250 \mathrm{~s}$ of reaction, some propene and ethylene are produced in small amounts $\left(\mathrm{p}_{\max }=12 \mathrm{~Pa}\right.$ ) as well as some $\mathrm{CO}_{2}$ (not visible on this scale). After around $\mathrm{t}=600 \mathrm{~s}, \mathrm{CO}$ production decreases, while conversion and hydrogen production still increase. Then after around $t=1000 \mathrm{~s}$ both hydrogen production and conversion decrease and reach a steady state.

Figure 4 shows the evolution of the $\mathrm{H}_{2} / \mathrm{CO}$ ratio with time for ethane, propane and propene. For propene oxidation, in the first 150 seconds of reaction, $\mathrm{H}_{2}$ and $\mathrm{CO}$ are produced in stoichiometric amounts $\left(\mathrm{H}_{2} / \mathrm{CO} \approx 1\right)$, then coke is formed. For propane and ethane, the $\mathrm{H}_{2} / \mathrm{CO}$ ratio levels at 1.5 and 1.8 respectively (between $t=300$ and 600 s for propane and $t=200$ s and 700s for ethane). During this lap of time, the conversions of both reactants increase considerably as seen in Figure 2. These $\mathrm{H}_{2} / \mathrm{CO}$ values are slightly higher but not far from the stoichiometric ratios one would obtain by conversion of propane and ethane to $\mathrm{CO}$ and $\mathrm{H}_{2}$ (1.33 and 1.5, respectively). The differences are due to the presence of other products $\left(\mathrm{CO}_{2}\right.$ and $\mathrm{H}_{2} \mathrm{O}$ ) and likely to some coke formation. In Figure 5 is reported the $\mathrm{CO}$ pressure measured during the oxidation of ethane and propane. After the maximum of $\mathrm{CO}$ production is reached, $\mathrm{H}_{2} / \mathrm{CO}$ (Fig. 4) increases steadily to $10-12$ indicating that a strong amount of coke is being formed, as confirmed by mass balance calculations.

As it can be seen in Figure 5 the rate of $\mathrm{CO}$ production does not depend on the nature of the alkane. Furthermore, both for ethane and propane, the trends followed by the conversion curves and those of $\mathrm{CO}$ production are similar as it can be seen from Figures 2 and 5. Finally, and contrary to what was observed during the oxidation of propane on BICUVOX and 
BICOVOX [13], replacing air by $\mathrm{O}_{2}$ in the $\mathrm{HOP}$ side of the membrane does not affect significantly the catalytic behaviour of BITAVOX-220 (Fig.6).

In all cases, these experiments could be reproduced, after briefly introducing air in LOP compartment in order to burn the coke deposited during the reaction. Ex-situ analysis of the membranes after test by SEM, XRD and XPS did not show any significant modification of the samples. The exception is an increase of the grains size by ca. $20 \%$, which is attributed to the long experimental periods the membranes had to face at elevated temperatures (typically several weeks at $\mathrm{T}>800 \mathrm{~K}$, for each sample).

\section{Discussion}

Low surface area BIMEVOX membranes have already proved to exhibit stable catalytic activity for hydrocarboon oxidation as in the case of propene oxidation on mirror-polished BICUVOX and BICOVOX membranes [11]. This is confirmed with BITAVOX-800 membrane for propane oxidation for which a stable steady state characterised by low conversions and formation of small amounts of propene and of syngas is reached (Figure 1). Experiments could be performed and repeated several times at various experimental conditions without formation of coke. The overall amount of $\mathrm{O}$ flowing through the membrane at steady state is two orders of magnitude higher then that permeating to $\mathrm{O}_{2}$ in the absence of hydrocarbon. This confirms, as suspected, that the recombination step is the limiting step of oxygen permeation to $\mathrm{O}_{2}$.

Increasing the active surface area - by polishing with 220 grit sandpaper - leads to an increase of the activity of BITAVOX in a spectacular way, as it was also observed for other BIMEVOX $(\mathrm{Me}=\mathrm{Cu}, \mathrm{Co})[11,13]$. However the higher conversion and selective production of syngas are obtained at the expense of steady and stable activity. The resulting transient phenomena clearly indicate that the surface and/or bulk of the membrane undergoes a 
transformation as if the oxygen supply through the membrane was not sufficient to compensate the increase of surface activity. In the very early stage of reaction (first $150-250$ s) with propane, the activity resembles that of BITAVOX-800 with the exception of some $\mathrm{CO}_{2}$ production. Then, in the rising part of the curves of conversion and $\mathrm{CO}$ pressure, $\mathrm{H}_{2} / \mathrm{CO}$ ratios close to those of stoichiometric syngas production from the respective reactants are observed. Figure 5 suggests that a definite amount of oxygen is available for CO production at this stage of the process. The overall amount of $\mathrm{CO}$ produced during the peak between 250 and $1300 \mathrm{~s}$ corresponds to approximately 100-120 $\mu$ moles CO. If the oxygen supply is supposed to come from the reduction of $\mathrm{V}^{5+}$ to $\mathrm{V}^{4+}$ species, such amounts would correspond to the reduction of an equivalent of 7-8 \% of the total $\mathrm{V}$ content of the membrane. Although it is difficult to determine the effective surface area developed by the membrane, it is not probable that such large amounts could correspond to the reduction of surface $\mathrm{V}$ exclusively. The amount of dioxygen which permeates through the membrane in absence of hydrocarbon $<10 \mathrm{ppm}$ is too small to account for the CO production but, in absence of hydrocarbon, as shown by isotope exchange depth profile technique [9], oxygen transfer is limited by slow kinetics of oxygen exchange at the surface. In presence of hydrocarbon, the surface of the membrane is no more the same and higher oxygen permeation fluxes could be expected. On the other hand, if the increase of oxygen flux in presence of the hydrocarbon was sufficient to account for the total CO produced, a steady activity should be observed as for BITAVOX800. As this is not the case for BITAVOX-220, a limitation to oxygen transfer through the membrane - probably due to low electronic conduction - must occur and it is therefore likely that sub-surface and/or bulk oxygen species are also involved in the catalytic reaction. However, this process does not lead to a deep reduction of the solid as no modification of the bulk (XRD) or of the surface composition (XPS) could be noticed. Another interesting aspect of the $\mathrm{CO}$ production curve is that it exactly matches that of conversion (Fig. 2 and 5). This 
suggests that, at this stage of the membrane evolution, the activation of the alkane is not the rate limiting step of the reaction. This one should involve either $\mathrm{CO}$ desorption or, more probably, the supply of oxygen species from the solid to form adsorbed $\mathrm{CO}$ which may desorb rapidly.

Even after the activity peak, that is when $\mathrm{H}_{2}$ and coke are the major products, several hundreds of ppm of $\mathrm{CO}$ are still produced. For example at $3000 \mathrm{~s}$ during propane oxidation on BITAVOX-220 (Fig. 3), pCO $\approx 27 \mathrm{~Pa}(270 \mathrm{ppm}$ ) which is of the same order of magnitude of the one measured on BITAVOX-800 after the same time of reaction $(\mathrm{pCO} \approx 17 \mathrm{~Pa}$, see Fig. 1). This shows that, even in these strongly reducing conditions, the bulk structure is maintained allowing for the $\mathrm{O}^{2-}$ diffusion through the membrane to proceed and thus explaining the good stability of the material.

The influence of the partial pressure of oxygen $\mathrm{pO}_{2}{ }^{\mathrm{HOP}}$ in the HOP compartment on the catalytic performance is worthwhile to examine (Fig 6). In the case of $\mathrm{Cu}$ and Co-doped BIMEVOX membranes, we have shown that the increase of $\mathrm{pO}_{2}{ }^{\mathrm{HOP}}$ (e.g., from air to pure $\mathrm{O}_{2}$ ) delayed the activity peak (and thus the formation of coke) of BICOVOX while it accelerated that of BICUVOX [13]. These different evolutions were interpreted in light of the semiconducting properties of the materials, as BICOVOX and BICUVOX are p-type and ntype, respectively, even though the number of charge carriers is low [14]. Conductivity measurements performed on BITAVOX showed that the electronic conductivity was very low and thus no definite $n$ - or p-type character could be inferred. This may explain that, in contrast to BICOVOX or BICUVOX, an increase of the oxygen pressure at HOP does not significantly affect the activity of BITAVOX-220. However, it cannot be excluded that surface phenomena also limit the reaction rate, in which case one could expect not to observe significant $\mathrm{O}_{2}$ pressure effects. 


\section{Conclusions}

$\mathrm{Bi}_{2} \mathrm{~V}_{0.8} \mathrm{Ta}_{0.2} \mathrm{O}_{5.5}$ (BITAVOX) membranes with intermediate surface roughness (800 grit $\mathrm{SiC}$ paper polishing) as compared to mirror-polished and unpolished surfaces are stable but show low activity $\left(\mathrm{C}_{\text {propane }}<2 \%\right.$ at $\left.923 \mathrm{~K}\right)$ and low selectivity to propene and syngas production.

Increasing the surface roughness (220 grit SiC paper polishing) proved to be very efficient in increasing considerably the catalytic activity as already observed for BICUVOX and BICOVOX. However, to explain the change of the catalytic regime and the variation of $\mathrm{H}_{2} / \mathrm{CO}$ ratio, it is necessary to consider that the $\mathrm{O}^{2-}$ diffusion through the membrane is not fast enough to compensate the conversion of propene, as well as that of less active molecules like propane or ethane. This evolution may involve restructuring of the material in the first layers of the LOP surface. However, no deep reduction $\left(\right.$ like $\mathrm{Bi}^{3+} \rightarrow \mathrm{Bi}^{0}, \mathrm{~V}^{5+} \rightarrow \mathrm{V}^{3+}$ ) occurs which would be irreversible because in such case the membrane could not be regenerated simply by burning the coke, and also because no experimental evidence could be obtained from characterisation. Indeed, even when coke and $\mathrm{H}_{2}$ become the major products, oxygen species still diffuse through the membrane otherwise there would be no conversion of hydrocarbon $(\mathrm{C}$ $\approx 5-10 \mathrm{~mol} \%$ ), which shows that the bulk structure of the BIMEVOX is maintained. When the conversion increases, BITAVOX shows very interesting catalytic properties both for propane and ethane valorisation, as syngas is produced with $\mathrm{H}_{2} / \mathrm{CO}$ ratios very close to those corresponding to the stoichiometric transformation of these alkanes.

Considering the high oxyde ion conductivity of these materials as compared to the electronic conductivity, one can expect the latter to be responsible for the observed limitations and thus for the membrane restructuring. Indeed, and although other limitations may not be excluded, the results obtained with BITAVOX membranes are consistent with those observed with BICUVOX and BICOVOX membranes. These results confirm the potential of BIMEVOX 
materials for oxidation catalysis in CDMR reactors. As far as bulk properties are concerned, these materials prove to be very stable over long experimental periods. Nevertheless difficulties remain to be overcome. In particular, the electronic conductivity should be improved in order to ensure sufficient oxygen supply to the LOP surface in order to face the high activity during the catalytic oxidation reactions.

\section{Acknowledgements}

The Centre National de la Recherche Scientifique, the Région Nord-Pas de Calais, and the Chevreul Federation (CNRS) are acknowledged for providing a grant to one of the authors (H. B.) and for financial support. Part of this work was performed in the frame of CONCORDE "Coordination of Nanostructured Catalytic Oxide Research and Development in Europe", an European Union funded concerted action $\left(6^{\text {th }}\right.$ Framework Programme).

\section{References}

[1] S. Azgui, F. Guillaume, B. Taouk and E. Bordes, Catal. Today, 25 (1995) 291.

[2] R. Di Cosimo, J.D. Burrington, R. K. Grasselli, J. Catal., 102 (1986) 234.

[3] C. Courson, B. Taouk, E. Bordes, Catal. Lett., 66 (2000) 129.

[4] G. Emig, M.A. Liauw, Topics in Catalysis, 21 (2002) 11.

[5] R. M. Contractor, H.E. Bergna, H.S. Horowitz., C.M. Blackstone, U. Chowdry, A.W. Sleight, Surf. Sci. Catal., 38 (1987) 645.

[6] E. Bordes-Richard, D. Vanhove, Y. Schuurman, C. Mirodatos, S. Miachon, J.-A. Dalmon D. Schweich, L'Actualité Chimique, may-june (2002) 64.

[7] R. M. Contractor, H. S. Horowitz, G. M. Sisler, E. Bordes., Catal. Today, 37 (1997) 51.

[8] F. Abraham, J.C. Boivin, G. Mairesse, G. Nowogrocki, Solid State Ionics, 40 (1990) 934. 
[9] R.-N. Vannier, S. J. Skinner, R. J. Chater, J. A. Kilner, G. Mairesse, Solid State Ionics, $160(2003) 85$.

[10] R.-N. Vannier, S. J. Skinner, R. J. Chater, J. A. Kilner, G. Mairesse., Solid State Ionics, $160(2003) 327$.

[11] A. Löfberg, S. Boujmiai, E. Capoen, M.C. Steil, C. Pirovano, R.N.Vannier, G. Mairesse, E. Bordes-Richard, Catal. Today, 91-92 (2004) 79.

[12] A. Chetouani, B. Taouk, E. Bordes-Richard, Catal. Today, 91-92 (2004) 75.

[13] A. Löfberg, C. Pirovano, M.C. Steil, R.N.Vannier, E. Bordes-Richard, Catal. Today, (2005) in press.

[14] J. Fouletier, C. Muller, E. Pernot, in J.L. Baptista, J.A. Labrincha, P.M. Vilarihno (Eds), Electroceramics V, University of Aveiro, 1996, p.37. 


\section{Figure captions}

Fig. 1: Evolution of the conversion of $\mathrm{C}_{3} \mathrm{H}_{8}$ and distribution of products vs time using BITAVOX-800 membrane $-\mathrm{T}=923 \mathrm{~K} ; \mathrm{HOP}=$ Air; $\mathrm{LOP}=\mathrm{He}+1 \% \mathrm{C}_{3} \mathrm{H}_{8}$

Fig. 2: Conversion of $\mathrm{C}_{3} \mathrm{H}_{8}, \mathrm{C}_{3} \mathrm{H}_{6}$ and $\mathrm{C}_{2} \mathrm{H}_{6}$ vs time using BITAVOX-220 membrane - $\mathrm{T}=$ $923 \mathrm{~K} ; \mathrm{HOP}=\mathrm{Air} ; \mathrm{LOP}=\mathrm{He}+1 \% \mathrm{HC}(\mathrm{HC}=$ hydrocarbon $)$.

Fig. 3: Evolution time of the conversion of $\mathrm{C}_{3} \mathrm{H}_{8}$ and distribution of products vs using BITAVOX-220 - T = $923 \mathrm{~K} ; \mathrm{HOP}=$ Air; $\mathrm{LOP}=\mathrm{He}+1 \% \mathrm{C}_{3} \mathrm{H}_{8}$

Fig. 4: $\mathrm{H}_{2} / \mathrm{CO}$ ratio vs time during the oxidation of $\mathrm{C}_{3} \mathrm{H}_{8}, \mathrm{C}_{3} \mathrm{H}_{6}$ and $\mathrm{C}_{2} \mathrm{H}_{6}$ on BITAVOX-220 $-\mathrm{T}=923 \mathrm{~K} ; \mathrm{HOP}=$ Air; $\mathrm{LOP}=\mathrm{He}+1 \% \mathrm{HC}$.

Fig 5: Evolution of the pressure of $\mathrm{CO}$ vs time during the oxidation of $\mathrm{C}_{3} \mathrm{H}_{8}$ and $\mathrm{C}_{2} \mathrm{H}_{6}$ on BITAVOX-220 $-\mathrm{T}=923 \mathrm{~K} ; \mathrm{HOP}=\mathrm{Air} ; \mathrm{LOP}=\mathrm{He}+1 \% \mathrm{HC}$

Fig. 6: Evolution of the pressures of $\mathrm{CO}$ and $\mathrm{H}_{2}$ (top) and of $\mathrm{C}_{3} \mathrm{H}_{8}$ conversion (bottom) vs time on BITAVOX-220: influence of $\mathrm{pO}_{2}$ in $\mathrm{HOP}-\mathrm{T}=948 \mathrm{~K} ; \mathrm{HOP}=$ Air (curves in black) or $\mathrm{O}_{2}$ (curves in gary); $\mathrm{LOP}=\mathrm{He}+1 \% \mathrm{C}_{3} \mathrm{H}_{8}$ 
Figure 1

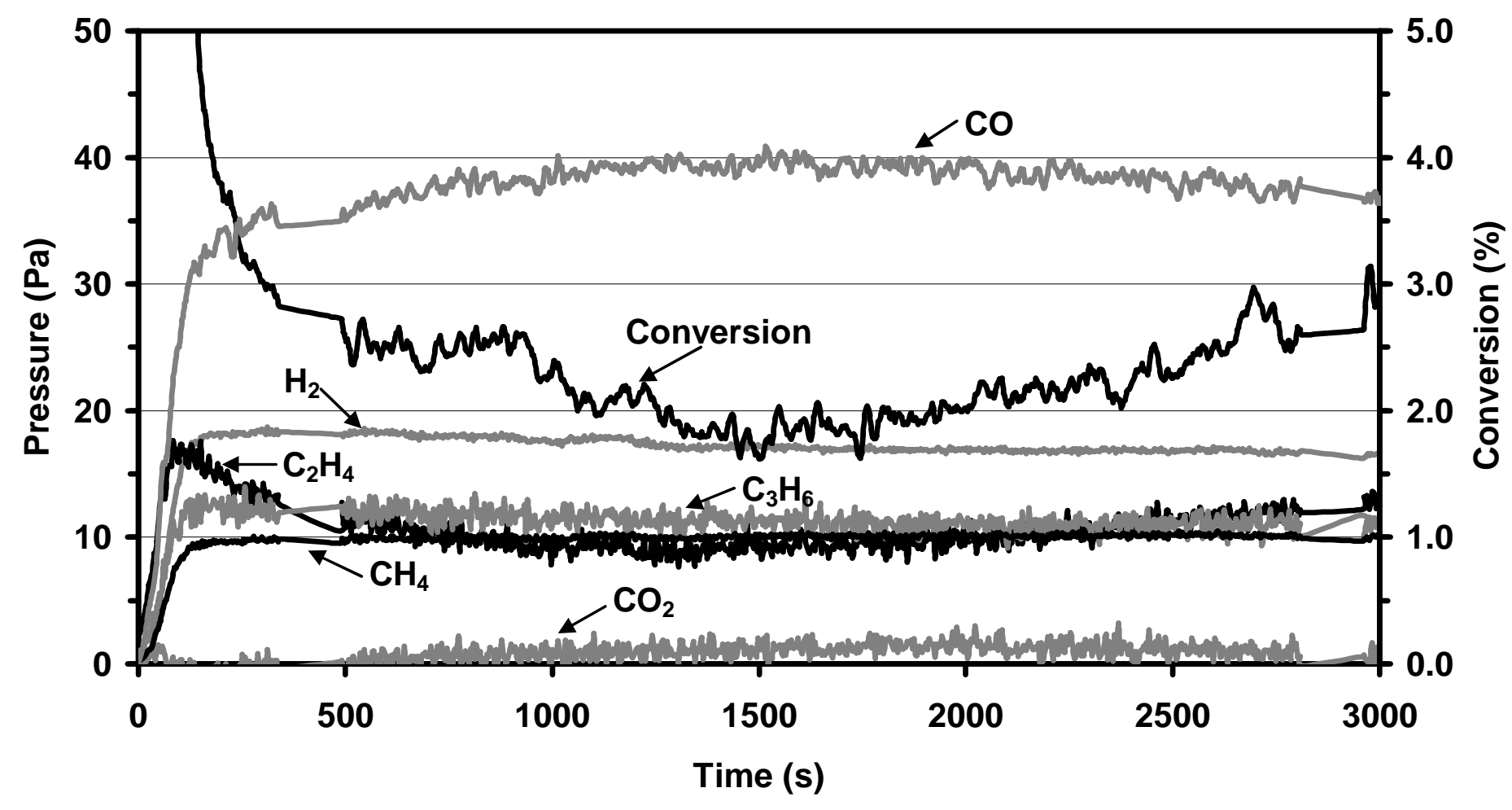


Figure 2

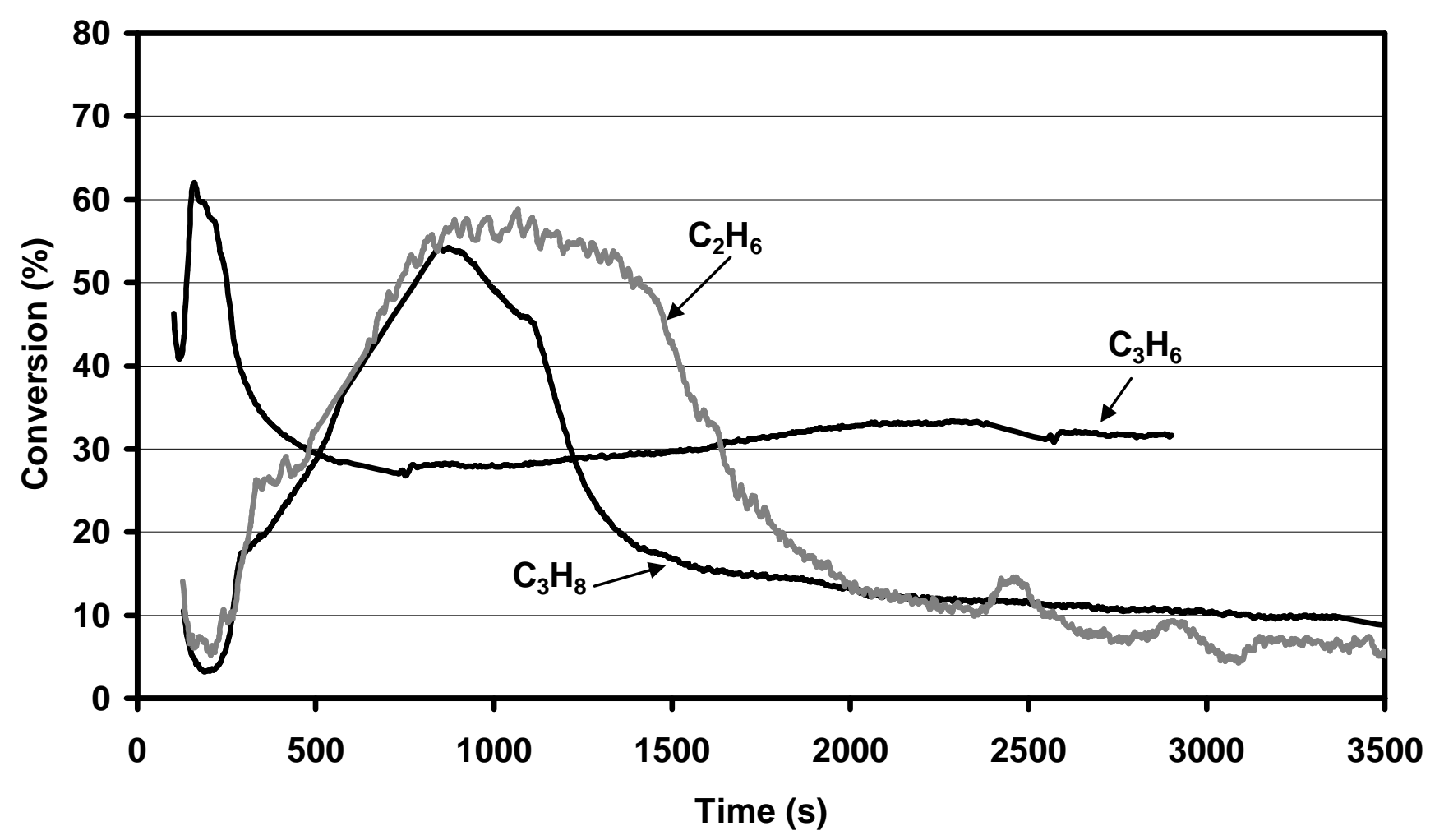


Figure 3

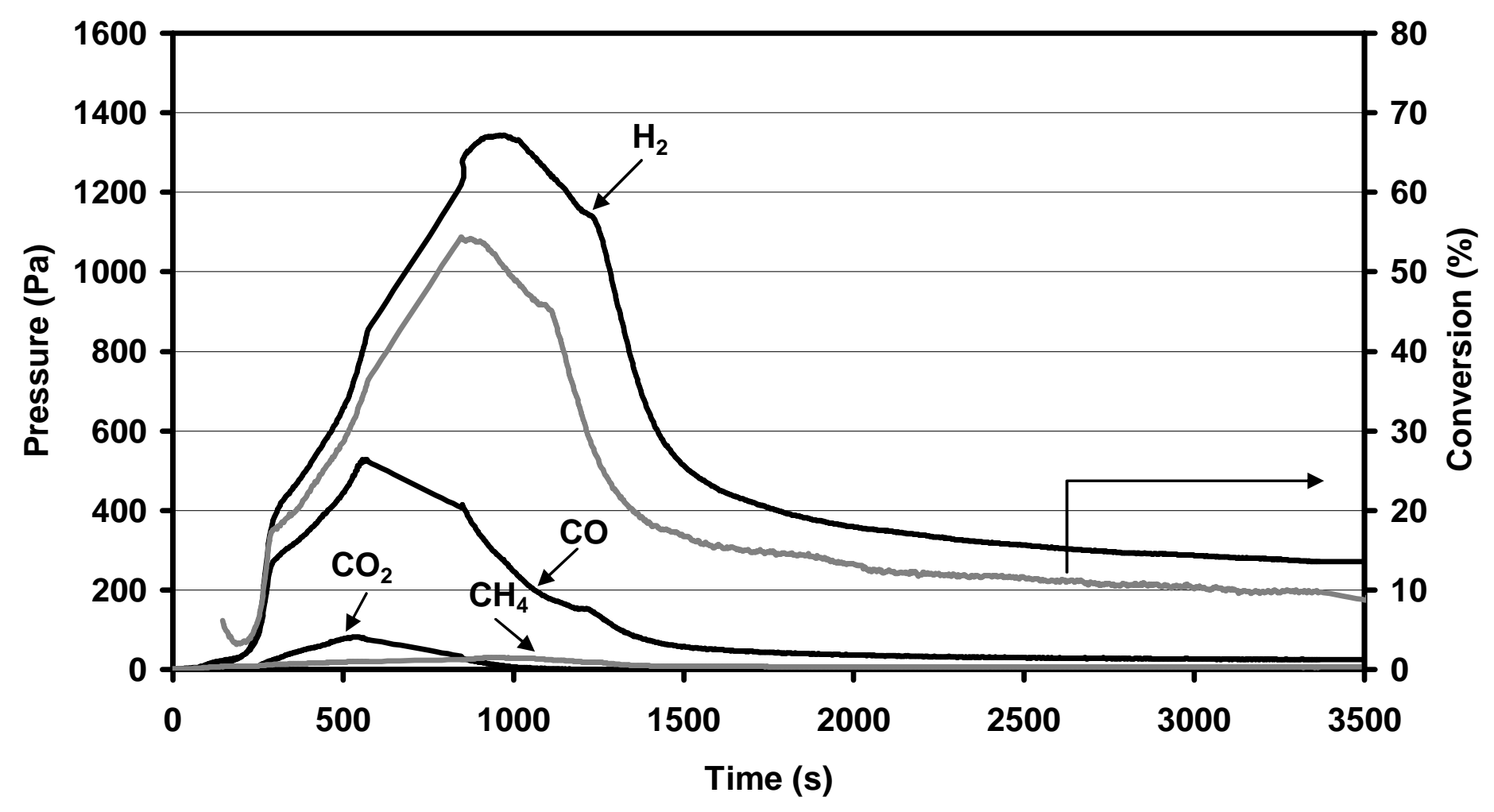


Figure 4

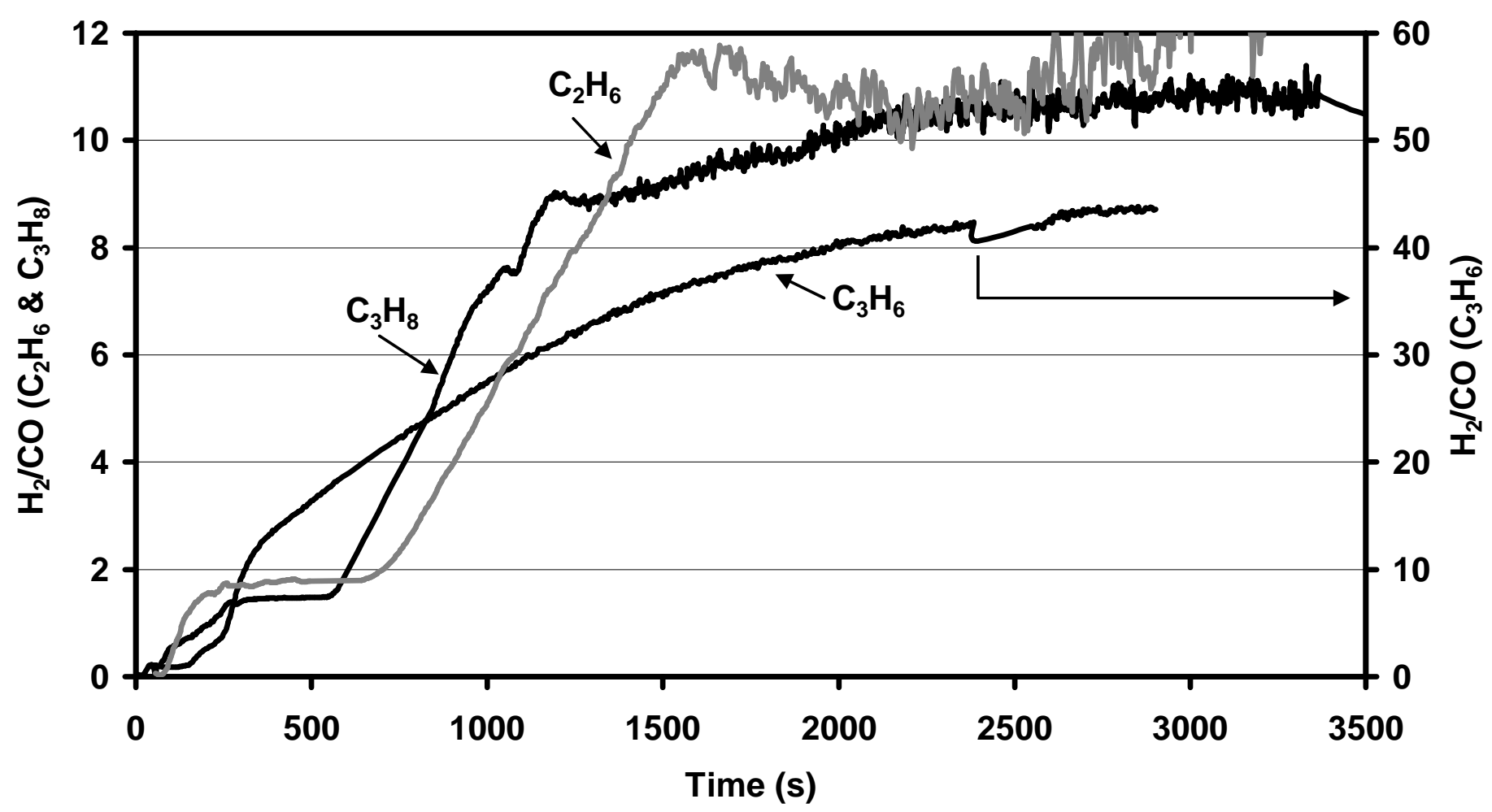


Figure 5

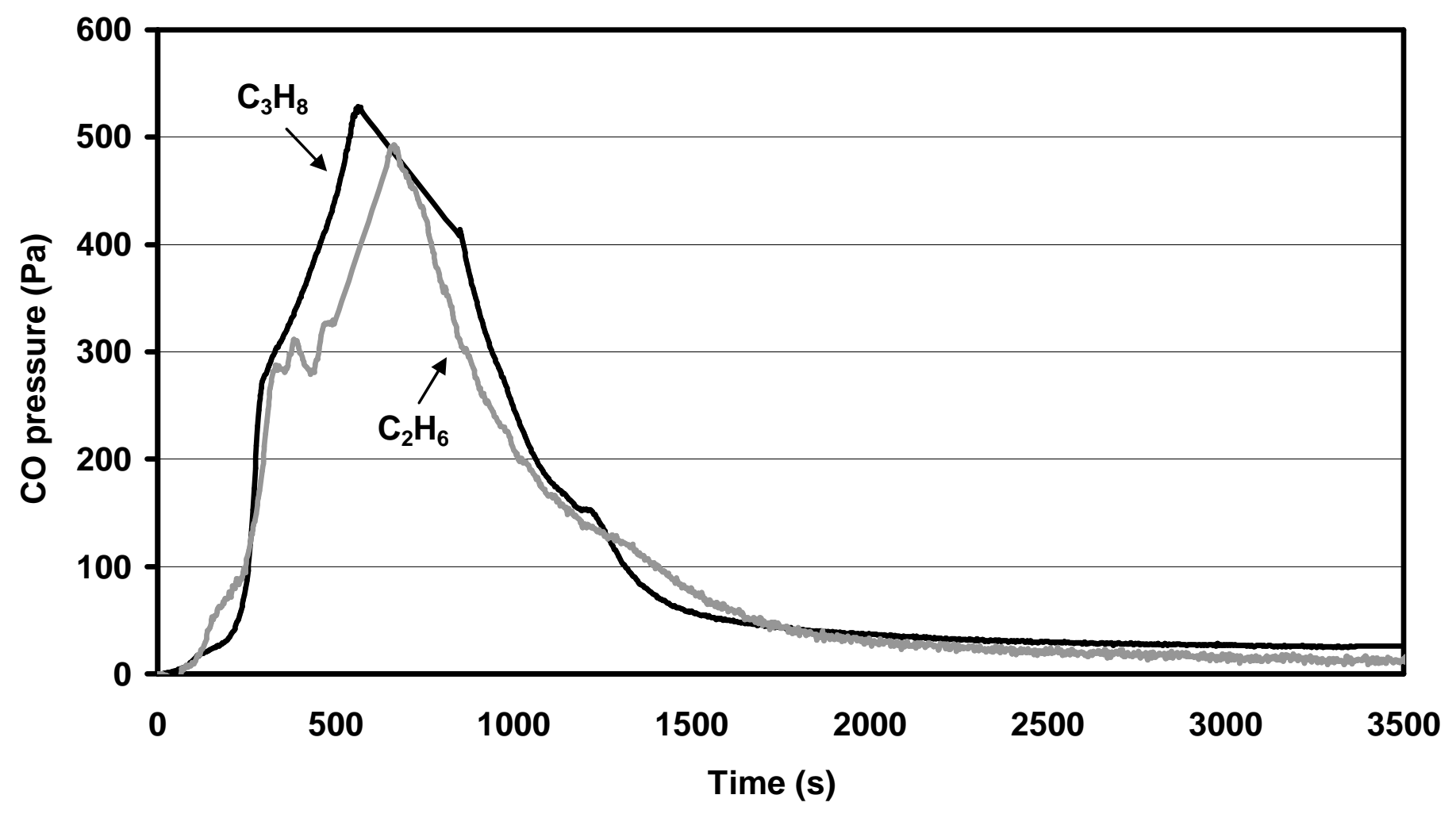


Figure 6

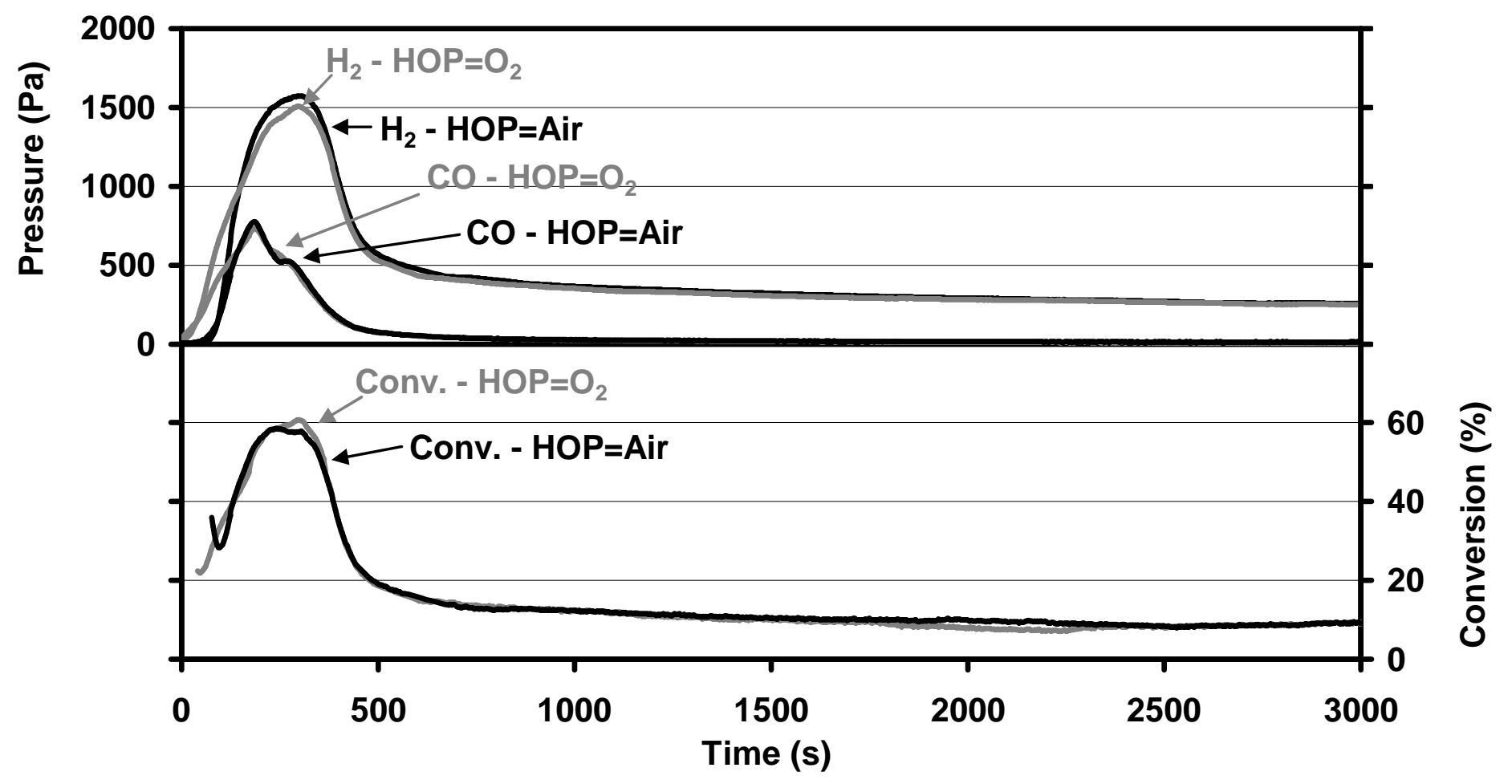

